Open Access

\title{
The relative importance of maternal body mass index and glucose levels for prediction of large-for-gestational-age births
}

Kerstin Berntorp ${ }^{1,2}$, Eva Anderberg ${ }^{3}$, Rickard Claesson ${ }^{1,4^{*}}$, Claes Ignell ${ }^{1,5}$ and Karin Källén ${ }^{3}$

\begin{abstract}
Background: The risk of gestational diabetes mellitus (GDM) increases substantially with increasing maternal body mass index (BMI). The aim of the present study was to evaluate the relative importance of maternal BMI and glucose levels in prediction of large-for-gestational-age (LGA) births.

Method: This observational cohort study was based on women giving birth in southern Sweden during the years 2003-2005. Information on 10974 pregnancies was retrieved from a population-based perinatal register. A 75-g oral glucose tolerance test (OGTT) was performed in the 28 week of pregnancy for determination of the 2-h plasma glucose concentration. BMI was obtained during the first trimester. The dataset was divided into a development set and a validation set. Using the development set, multiple logistic regression analysis was used to identify maternal characteristics associated with LGA. The prediction of LGA was assessed by receiver-operating characteristic (ROC) curves, with LGA defined as birth weight $>+2$ standard deviations of the mean.

Results: In the final multivariable model including BMI, 2-h glucose level and maternal demographics, the factor most strongly associated with LGA was BMI (odds ratio 1.1, $95 \%$ confidence interval [CI] 1.08-1.30). Based on the total dataset, the area under the ROC curve (AUC) of 2-h glucose level to predict LGA was 0.54 (95\% Cl 0.48-0.60), indicating poor performance. Using the validation database, the AUC for the final multiple model was 0.69 (95\% Cl 0.66-0.72), which was identical to the AUC retrieved from a model not including 2-h glucose $(0.69,95 \% \mathrm{Cl} 0.66-0.72)$, and larger than from a model including 2-h glucose but not BMI (0.63, $95 \% \mathrm{Cl} 0.60-0.67)$.

Conclusions: Both the 2-h glucose level of the OGT and maternal BMI had a significant effect on the risk of LGA births, but the relative contribution was higher for BMI. The findings highlight the importance of concentrating on healthy body weight in pregnant women and closer monitoring of weight during pregnancy as a strategy for reducing the risk of excessive fetal growth.
\end{abstract}

Keywords: Body mass index, Gestational diabetes mellitus, Glucose levels, Large-for-gestational-age, Oral glucose tolerance test, Predicting risk

\footnotetext{
* Correspondence: rickard.claesson@med.lu.se

'Department of Clinical Sciences Malmö, Lund University, Malmö, Sweden

${ }^{4}$ Department of Obstetrics and Gynecology, Office for Healthcare "Kryh",

Ystad SE-27182, Sweden

Full list of author information is available at the end of the article
}

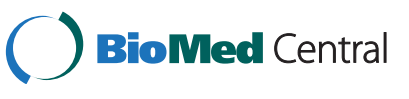

(C) 2015 Berntorp et al. Open Access This article is distributed under the terms of the Creative Commons Attribution 4.0 International License (http://creativecommons.org/licenses/by/4.0/), which permits unrestricted use, distribution, and reproduction in any medium, provided you give appropriate credit to the original author(s) and the source, provide a link to the Creative Commons license, and indicate if changes were made. The Creative Commons Public Domain Dedication waiver (http://creativecommons.org/publicdomain/zero/1.0/) applies to the data made available in this article, unless otherwise stated. 


\section{Background}

Obesity is an increasing health problem, and affects up to one-third of women of reproductive age in the western world [1]. The risk of gestational diabetes mellitus (GDM) increases substantially with increasing maternal body mass index (BMI) [2]. Moreover, GDM and maternal obesity are independently associated with adverse neonatal outcomes, in particular macrosomia and largefor-gestational-age (LGA) births [3-5], which in turn increase the risk of complications in both the mother and the newborn [6]. For the mother this includes prolonged labour, perineal lacerations, uterine atonia, abnormal haemorrhage and caesarean section [6, 7]. Neonatal complications consist of birth trauma associated with shoulder dystocia, hypoglycaemia, respiratory distress and may also result in impairment to health later in life [6, 7]. Antenatal detection of large fetuses makes it possible to intervene by induction of labour or caesarean section, thereby preventing the birth of macrosomic newborns or complications associated with vaginal delivery of large babies. Surkan et al. reported an unadjusted increase in LGA births in Sweden of $23 \%$ over the years 1992-2001. The increasing trend could mainly be explained by concurrent increases in maternal BMI and decreases in maternal smoking [8]. The prevalence of maternal smoking has declined continuously in Sweden during the last decades with an annual change of $7.2 \%$ between 2000 and 2008 [9].

Universal screening for GDM by an oral glucose tolerance test (OGTT) has been performed at the general antenatal clinics in southern Sweden since 1995. The screening program is well implemented and has previously shown high adherence, with $93 \%$ of eligible women being screened [10]. During the years 2003-2005, pregnant women representing different glucose categories according to the 2-h glucose level of the OGTT were invited to take part in a follow-up program, the Mamma Study. The pregnancy outcomes of the participating women have been reported previously, indicating that even limited degrees of maternal hyperglycemia affect the outcome and increase the risk of LGA births [11]. During the period of recruitment to the Mamma Study, a large number of test results from the antenatal clinics were made available. These form the basis of the present study. The purpose was to evaluate the relative importance of BMI and glucose levels in prediction of LGA births in a large sample of the pregnant population, also taking other risk factors into account by adding information on maternal characteristics.

\section{Methods}

\section{GDM screening}

The screening program for GDM in southern Sweden has been described in detail previously [11]. Briefly, a 75-g OGTT is offered to all women in the 28 week of gestation, and is done after overnight fasting at their local antenatal clinic. The diagnostic criteria for GDM are a simplification of those recommended by the European Association for the Study of Diabetes, omitting the initial fasting glucose sample and defining GDM as a 2-h capillary blood glucose concentration of $\geq 9.0 \mathrm{mmol} / \mathrm{L}$ [12]. In 2004, routine glucose measurements in Sweden were switched from blood glucose measurements to plasma glucose measurements, and a transformation factor of 1.11 was agreed on [13], resulting in a 2-h threshold value of $10.0 \mathrm{mmol} / \mathrm{L}$ for capillary plasma glucose to define GDM. The HemoCue blood glucose system (HemoCue $\mathrm{AB}$, Ängelholm, Sweden) is used to obtain immediate analysis of glucose concentrations. If 2-h capillary plasma glucose concentration is $8.9-9.9 \mathrm{mmol} / \mathrm{L}$, indicating gestational impaired glucose tolerance (IGT), the OGTT is repeated within a week. Normal glucose tolerance during pregnancy is defined as a 2-h capillary plasma glucose concentration $<8.9 \mathrm{mmol} / \mathrm{L}$.

\section{Study population}

Recruitment to the Mamma Study took place in 2003-2005, and involved four of the five delivery departments in the county of Skåne in southern Sweden; details have been described previously [11]. During the recruitment period, OGTT results from the local antenatal clinics were sent to the study coordinator (EA), enabling identification of the test results of women who consented to be enrolled; it also ensured correct sampling technique [10]. Initially, 11976 OGTT results in total were reported. If a woman had repeated pregnancies during the period, only the first one was included. Likewise, if a repeat OGTT was performed, only the first one was included.

Participating women received standard obstetric care as long as their OGTT values were normal. Women diagnosed with GDM were transferred to specialist antenatal care and had regular contact with a diabetologist. They were given advice on diet and physical exercise, and they were closely monitored through self-testing of blood glucose. If treatment goals for blood glucose were not achieved, insulin treatment was added. Women diagnosed with gestational IGT were given advice on diet and physical exercise, but followed the routine pregnancy program, unless a repeat OGTT was diagnostic of GDM.

The study was carried out in accordance with the Declaration of Helsinki. Written informed consent was obtained from all participants and the study protocol was approved by the Ethics Committee of Lund University (LU 259-00).

\section{Perinatal Revision South (PRS)}

Population-based information was retrieved from the regional perinatal database, Perinatal Revision South (PRS), 
which was established in 1995 for quality assurance in perinatal care in the southern region of Sweden [14]. The PRS is based on approximately 18000 annual births, and is compiled from data reported by all delivery and neonatal units in the region. The maternal pregnancy characteristics used as exposure variables were maternal age at delivery, parity, BMI, maternal height and maternal smoking. Information about BMI $\left(\mathrm{kg} / \mathrm{m}^{2}\right)$ was based on weight and height measured at the first prenatal visit in the first trimester. Gestational age was estimated from expected date of parturition according to ultrasound in the first half of gestation. LGA births, small-for-gestational-age (SGA) births and adequate-for-gestational-age (AGA) births were defined as birth weight greater than +2 standard deviations (SD), less than $-2 \mathrm{SD}$ and between $-2 \mathrm{SD}$ and $+2 \mathrm{SD}$ of the expected birth weight for gestational age and gender, respectively, according to the Swedish reference curve for fetal growth [15]. Of the 11976 OGTT results, information in the PRS was available for a total of 11016 pregnancies. When we evaluated the risk factors for LGA, infants with unavailable LGA information were excluded, and this restricted dataset was the basis of the present evaluation $(n=10974)$. The dataset was divided into two parts, with every second woman belonging to the development dataset or the validation dataset.

Table 1 Maternal and infant characteristics according to glucose quartiles, and the corresponding 2-h plasma glucose level

\begin{tabular}{|c|c|c|c|c|c|c|c|c|c|c|c|}
\hline \multirow[t]{2}{*}{ Glucose quartiles (mmol/L) } & \multicolumn{2}{|l|}{$<5.7$} & \multicolumn{2}{|c|}{$5.7-6.4$} & \multicolumn{2}{|c|}{$6.5-7.2$} & \multicolumn{2}{|l|}{$>7.20$} & \multicolumn{2}{|c|}{ 2-h Glucose (mmol/L) } & \multirow[t]{2}{*}{$p^{a}$} \\
\hline & $n$ & $\%$ & $n$ & $\%$ & $n$ & $\%$ & $n$ & $\%$ & mean & $95 \% \mathrm{Cl}$ & \\
\hline Total & 2637 & 23.9 & 2783 & 25.3 & 2819 & 25.6 & 2777 & 25.2 & & & \\
\hline Maternal age, years & & & & & & & & & & & $<0.001$ \\
\hline$<20$ & 80 & 32.5 & 62 & 25.2 & 63 & 25.6 & 41 & 16.7 & 6.2 & $6.1-6.4$ & \\
\hline $20-34$ & 2148 & 24.2 & 2288 & 25.8 & 2264 & 25.5 & 2180 & 24.5 & 6.5 & $6.4-6.5$ & \\
\hline$\geq 35$ & 409 & 21.6 & 433 & 22.9 & 492 & 26.0 & 556 & 29.4 & 6.6 & $6.6-6.7$ & \\
\hline Parity & & & & & & & & & & & 0.09 \\
\hline 1 & 128 & 23.8 & 134 & 24.9 & 141 & 26.2 & 135 & 25.1 & 6.5 & $6.4-6.5$ & \\
\hline $2-3$ & 119 & 24.1 & 128 & 26.0 & 124 & 25.2 & 122 & 24.7 & 6.5 & $6.4-6.5$ & \\
\hline$\geq 4$ & 16 & 24.1 & 15 & 22.5 & 15 & 23.4 & 20 & 30.0 & 6.6 & $6.5-6.7$ & \\
\hline Smoker & & & & & & & & & & & $<0.001$ \\
\hline No & 2220 & 23.4 & 2408 & 25.4 & 2430 & 25.6 & 2424 & 25.6 & 6.5 & $6.5-6.5$ & \\
\hline Yes & 341 & 27.2 & 309 & 24.6 & 333 & 26.6 & 271 & 21.6 & 6.3 & $6.3-6.4$ & \\
\hline Maternal BMI, kg/m² & & & & & & & & & & & $<0.001$ \\
\hline$<18.5$ & 50 & 25.6 & 50 & 25.6 & 50 & 25.6 & 45 & 23.1 & 6.4 & $6.3-6.6$ & \\
\hline $18.5-24$ & 1496 & 25.1 & 1569 & 26.3 & 1542 & 25.9 & 1351 & 22.7 & 6.4 & $6.4-6.4$ & \\
\hline $25.0-29.9$ & 585 & 22.0 & 641 & 24.1 & 687 & 25.9 & 743 & 28.0 & 6.6 & $6.5-6.6$ & \\
\hline $30-34.9$ & 182 & 20.8 & 187 & 21.4 & 223 & 25.5 & 281 & 32.2 & 6.6 & $6.6-6.7$ & \\
\hline$\geq 35$ & 83 & 20.1 & 103 & 25.0 & 93 & 22.6 & 133 & 32.3 & 6.8 & $6.7-6.9$ & \\
\hline Gestational age, weeks & & & & & & & & & & & 0.006 \\
\hline$<37$ & 117 & 20.0 & 148 & 25.3 & 153 & 26.2 & 167 & 28.5 & 6.7 & $6.5-6.8$ & \\
\hline $37-41+6$ & 2345 & 24.0 & 2472 & 25.3 & 2502 & 25.6 & 2452 & 25.1 & 6.5 & $6.4-6.5$ & \\
\hline$\geq 42+0$ & 175 & 26.5 & 163 & 24.7 & 164 & 24.8 & 158 & 23.9 & 6.4 & $6.3-6.5$ & \\
\hline Weight for gestational age & & & & & & & & & & & $<0.001$ \\
\hline SGA & 69 & 23.2 & 80 & 26.9 & 68 & 22.9 & 80 & 26.9 & 6.5 & $6.4-6.7$ & \\
\hline AGA & 2446 & 24.2 & 2577 & 25.5 & 2578 & 25.6 & 2495 & 24.7 & 6.5 & $6.4-6.5$ & \\
\hline LGA & 115 & 20.1 & 110 & 19.2 & 156 & 27.3 & 191 & 33.4 & 6.7 & $6.6-6.9$ & \\
\hline Infant gender & & & & & & & & & & & 0.9 \\
\hline Male & 1407 & 24.5 & 1415 & 24.5 & 1437 & 25.0 & 1479 & 25.8 & 6.5 & $6.4-6.5$ & \\
\hline Female & 1228 & 23.4 & 1359 & 25.8 & 1379 & 26.2 & 1292 & 24.6 & 6.5 & $6.5-6.5$ & \\
\hline
\end{tabular}




\section{Statistical analysis}

Differences in glucose levels between groups were assessed using the Kruskal-Wallis test.

Chi-squared tests were performed to test possible differences between the datasets regarding maternal and infant characteristics (i.e. the development dataset and the validation dataset). The correlation between maternal BMI and 2-h glucose levels was estimated using the Pearson rho, and the linear relationship was estimated using a simple linear regression.

The prediction model for LGA was developed on the development dataset using univariate and multivariable logistic regression analyses. The variables tested were: maternal age (in years; continuous variable), parity 1 , parity $\geq 4$ (with parity $2-3$ as reference), maternal smoking (yes/no), maternal BMI (in $\mathrm{kg} / \mathrm{m}^{2}$; continuous), maternal height (in $\mathrm{cm}$; continuous), and glucose levels (in $\mathrm{mmol} / \mathrm{L}$; continuous). Models including class variables or second-degree polynomials were tested, but were abandoned as they performed worse than the models including the linear, continuous variables mentioned. Variables with a crude $p$-value of $<0.05$ in their association with LGA in the univariate model were entered into a multiple model, and variables with a $p$-value of $<0.05$ in the multiple model were entered into the final multiple model. A twosided $p$-value of less than 0.05 was considered statistically significant.

The results obtained from the final multiple model, and two other models for comparison, were applied to the validation dataset. The performance of each model was evaluated by studying the area under the receiveroperating characteristics (ROC) curve (AUC). The variance of each AUC was computed using the method proposed by DeLong et al. [16].

All statistical analyses were performed using Gauss (Gauss"; ${ }^{\mathrm{nw}}$; Aptec Systems Inc., Maple Valley, WA, USA; http://www.aptech.com).

\section{Results}

The frequency of maternal and infant characteristics according to glucose quartile and the corresponding mean 2-h plasma glucose levels are given in Table 1. Of the 2777 women with glucose levels in the upper quartile, 120 ( $1.1 \%$ of all women) fulfilled the glucose threshold for GDM (2-h plasma glucose concentration $\geq$ $10.0 \mathrm{mmol} / \mathrm{L})$ and 301 (2.7 \% of all women) fulfilled the glucose threshold for gestational IGT (2-h plasma glucose concentration 8.9-9.9 mmol/L). A linear regression analysis showed a weak, albeit statistically significant, linear association between maternal BMI and glucose levels (increase of 2-h plasma glucose per each BMI-unit: 0.022; $95 \%$ CI 0.017-0.028), with a statistically significant, but weak correlation coefficient (Pearson rho: 0.074; $95 \%$
CI: 0.056-0.093). A ROC curve based on the total dataset revealed that the ability of the 2-h glucose levels to predict LGA births was poor; AUC was 0.54 (95\% CI 0.48-0.60) (Fig. 1). Furthermore, there was no apparent natural cutoff point above which there would be an increased risk of LGA in the infant.

The maternal and infant characteristics of the development and validation groups are given in Table 2. The demographic characteristics of the groups were similar, but by chance there were significantly more women with BMI above 35, and SGA infants, in the development dataset than in the validation dataset.

Table 3 shows the odds ratios for LGA obtained from univariate and multiple logistic regression analyses based on the development sample. In the univariate analysis, all the factors evaluated except height $(p=0.0831$, not shown) and parity $\geq 4$ were significantly associated with LGA. In the first multiple model (including all the significant variables), all variables except maternal age remained significant. In the final multiple model, excluding maternal age, the factor most strongly associated with LGA was BMI $\left(p=2.6 \times 10^{-19}\right)$, accounting for $4.3 \%$ of the variance in the univariate setting $\left(R^{2}=0.043\right)$. Using the validation database, the AUC for the final multiple model was 0.69 (95\% CI 0.66-0.72), which was identical to the AUC retrieved from a model not including 2-h glucose (AUC 0.69 [95\% CI 0.66-0.72]), and larger than from a model including 2-h glucose but not BMI (AUC 0.63 [95 \% CI 0.60-0.67]).

The overall abilities of the three models developed in predicting LGA in the validation sample were illustrated

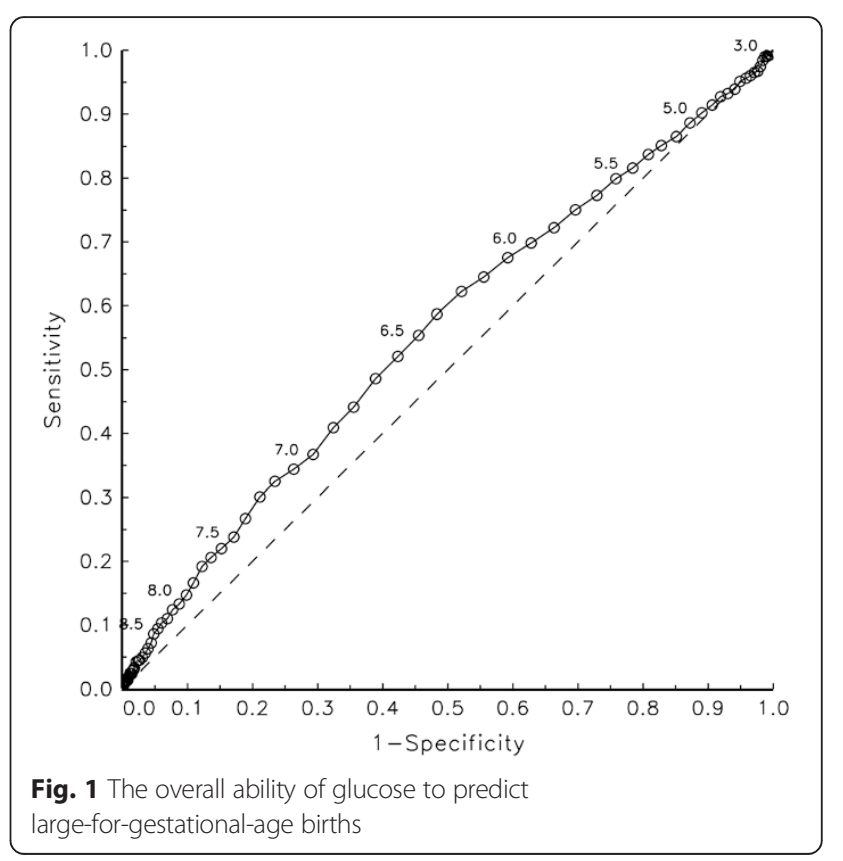


Table 2 Demographic characteristics of development sample and validation sample groups

\begin{tabular}{|c|c|c|c|c|c|}
\hline \multirow{2}{*}{$\frac{\text { Characteristic }}{\text { Maternal age, years }}$} & \multicolumn{2}{|c|}{ Development sample $(n=5487)$} & \multicolumn{2}{|c|}{ Validation sample $(n=5487)$} & \multirow{2}{*}{$\frac{p^{a}}{0.88}$} \\
\hline & 29.7 & 5.1 & 29.6 & 5.1 & \\
\hline$<20$ & 121 & $(2.2)$ & 125 & $(2.3)$ & 0.80 \\
\hline $20-34$ & 4415 & $(80.5)$ & 4426 & $(80.7)$ & 0.79 \\
\hline$\geq 35$ & 951 & $(17.3)$ & 936 & $(17.1)$ & 0.71 \\
\hline \multicolumn{6}{|l|}{ Parity } \\
\hline 1 & 2688 & $(49.0)$ & 2681 & $(48.9)$ & 0.90 \\
\hline $2-3$ & 2463 & $(44.9)$ & 2465 & $(44.9)$ & 0.97 \\
\hline$\geq 4$ & 336 & $(6.1)$ & 341 & $(6.2)$ & 0.84 \\
\hline \multicolumn{6}{|l|}{ Smoker } \\
\hline No & 4727 & $(86.1)$ & 4722 & $(86.1)$ & 0.89 \\
\hline Yes & 625 & $(11.4)$ & 623 & $(11.4)$ & 0.96 \\
\hline Maternal BMI, kg/m² & 24.9 & 4.5 & 24.7 & 4.3 & 0.089 \\
\hline$<18.5$ & 102 & (1.9) & 92 & $(1.7)$ & 0.47 \\
\hline $18.5-24$ & 2928 & $(53.4)$ & 3015 & $(54.9)$ & 0.095 \\
\hline $25.0-29.9$ & 1303 & $(23.7)$ & 1343 & $(24.5)$ & 0.37 \\
\hline $30-34.9$ & 440 & (8.0) & 424 & $(7.7)$ & 0.57 \\
\hline$\geq 35$ & 236 & $(4.3)$ & 175 & $(3.2)$ & 0.002 \\
\hline Gestational age, weeks & 39.7 & 1.7 & 39.7 & 1.7 & 0.62 \\
\hline$<37$ & 304 & $(5.5)$ & 281 & $(5.1)$ & 0.33 \\
\hline $37-41+6$ & 4875 & $(88.8)$ & 4889 & $(89.1)$ & 0.67 \\
\hline$\geq 42+0$ & 308 & (5.6) & 317 & (5.8) & 0.71 \\
\hline \multicolumn{6}{|c|}{ Weight for gestational age } \\
\hline SGA & 166 & (3.0) & 131 & $(2.4)$ & 0.04 \\
\hline AGA & 5044 & $(91.9)$ & 5061 & $(92.2)$ & 0.58 \\
\hline LGA & 277 & $(5.0)$ & 295 & $(5.4)$ & 0.44 \\
\hline \multicolumn{6}{|l|}{ Infant gender } \\
\hline Male & 2839 & $(51.7)$ & 2888 & $(52.6)$ & 0.35 \\
\hline Female & 2648 & $(48.3)$ & 2599 & $(47.4)$ & 0.35 \\
\hline
\end{tabular}

Both groups contain only information where all information was available. Data are $\mathrm{n}(\%)$ or mean (SD)

$A G A$ adequate for gestational age, $B M I$ body mass index, LGA large-for-gestational-age, SGA small-for-gestational-age

${ }^{a} p$-values obtained by chi-squared test (1 DF) for class variables and by Mann-Whitney U-test for continuous data

Table 3 Risk factors for large-for-gestational-age infants in development sample, using univariate and multiple logistic regression analysis

\begin{tabular}{|c|c|c|c|c|c|c|c|}
\hline \multirow[b]{2}{*}{ Risk factor } & \multicolumn{2}{|c|}{ Univariate model } & \multicolumn{2}{|c|}{ Multiple model } & \multicolumn{3}{|c|}{ Final multiple model } \\
\hline & $\mathrm{OR}$ & $p$ & $\mathrm{OR}$ & $p$ & $\mathrm{OR}$ & $95 \% \mathrm{Cl}$ & $p$ \\
\hline Maternal age (per 1-year increase) & 1.04 & 0.005 & 1.01 & 0.677 & & & \\
\hline Body mass index (per 1-step increase) & 1.11 & $<0.001$ & 1.10 & $<0.001$ & 1.10 & $1.08-1.13$ & $<0.001$ \\
\hline 2-h glucose (per 1 mmol increase) & 1.12 & 0.003 & 1.09 & 0.033 & 1.09 & $1.01-1.18$ & 0.028 \\
\hline Smoker & 0.31 & $<0.001$ & 0.29 & $<0.001$ & 0.29 & $0.16-0.52$ & $<0.001$ \\
\hline Parity 1 & 0.48 & $<0.001$ & 0.52 & $<0.001$ & 0.51 & $0.40-0,67$ & $<0.001$ \\
\hline Parity $\geq 4$ & 0.98 & 0.917 & & & & & \\
\hline
\end{tabular}

Multiple model included variables with $p<0.05$ in univariate model. Final multiple model included variables with $p<0.05$ in primary multiple model $O R$ odds ratio, $\mathrm{Cl}$ confidence interval 
using ROC curves (Fig. 2). The figure clearly shows that the ROC curve based on the model including BMI, nulliparity and maternal smoking was identical to that based on the model in which glucose levels were also added, whereas the performance of the model that included glucose levels but not BMI was considerably poorer.

\section{Discussion}

The main findings of the present study were that both the 2-h glucose level of the OGTT and maternal BMI had a significant effect on the risk of delivering an LGA neonate. However, the relative contribution was much higher for BMI, even when taking other risk factors into account. The overall ability of the developed model to predict LGA in the validation sample was satisfactory, but was identical to that of a model that did not include the 2-h glucose level.

The lack of internationally uniform diagnostic criteria for GDM, and the lack of agreement regarding what glucose levels should define normal glucose tolerance during pregnancy, hampers comparisons between studies [17]. Similar to our study, using the 2-h threshold of the WHO 1999 criteria to define normal glucose tolerance during pregnancy [18], a Danish study investigated the relationship between pregnancy outcome and pregnancy overweight or obesity in 2459 women with normal glucose tolerance during pregnancy [19]. After adjustment for various risk indicators, including the 2-h glucose value during the OGTT, they found a progressively increased risk of LGA births in overweight and obese women. However, they did not evaluate the corresponding effect of glucose levels when controlling for BMI and

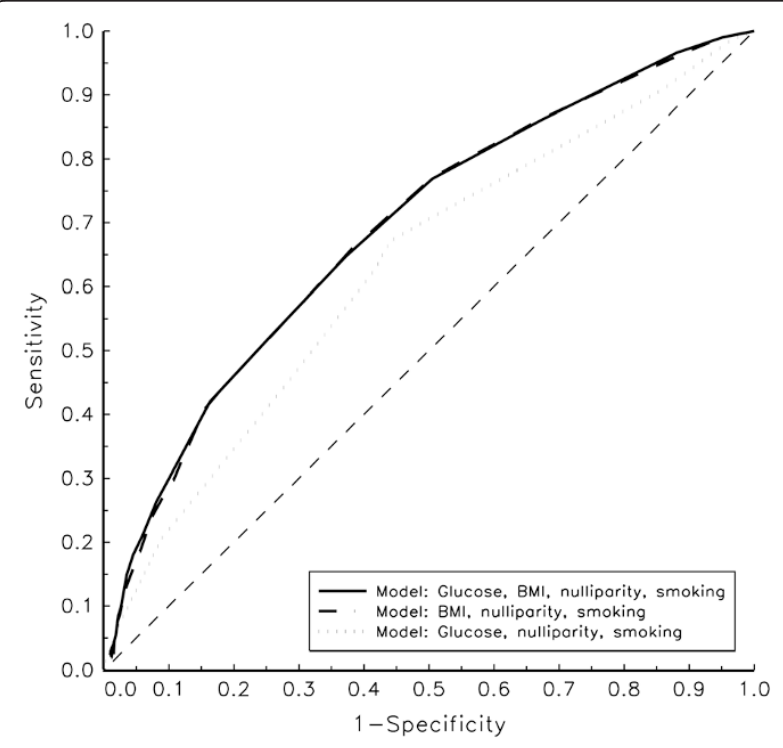

Fig. 2 ROC curves obtained after application of the three prediction models based on the validation data other risk indicators. It should be noted that the LGA was defined as birth weight above the ninetieth percentile for the reference population, which differed from the one used in the current study (approximately equivalent to the 97.5 th percentile).

Based on the ROC curve of the total dataset, we found no apparent natural cutoff point above which there would be an increased risk of having an LGA infant. This is in line with the Hyperglycemia and Adverse Pregnancy Outcomes (HAPO) Study, which showed that maternal hyperglycemia is associated with perinatal risk in a linear way, with no obvious threshold [20]. In a post hoc analysis using the International Association of Diabetes and Pregnancy Study Groups (IADPSG) criteria for GDM [21], OR for birth weight greater than the ninetieth percentile was somewhat higher in non-obese GDM women $(2.19,95 \%$ CI 1.93-2.47) than in obese non-GDM women $(1.73,95 \%$ CI 1.50-2.0) relative to non-obese non-GDM women, controlling for other potential risk factors [4]. Whereas all other guidelines for the diagnosis of GDM are more or less based on arbitrary statistics, the IADPSG criteria are for the first time based on perinatal outcomes [22]. According to these criteria, at least one of the fasting, 1-h or 2-h venous plasma glucose thresholds during a 75-g OGTT (5.1, 10.0 or $8.5 \mathrm{mmol} / \mathrm{L}$, respectively) must be equalled or exceeded to make a GDM diagnosis. Use of the individual glucose thresholds fasting, 1-h and $2 \mathrm{~h}$ identified 55 , 55 and $38 \%$, respectively, of the total HAPO cohort [23]. Although it is not regarded as a diagnostic standard [21], capillary glucose samples are widely used for diagnostic purposes in Sweden. According to a recently presented conversion algorithm, the capillary 2-h threshold value of $10.0 \mathrm{mmol} / \mathrm{L}$ - used in most parts of Sweden to define GDM [24] - coincides with the venous 2-h threshold value proposed by the IADPSG [25]. From this, it is obvious that the simplified method, omitting the initial fasting glucose sample during the OGTT, is not optimal for prediction of gestational weight of the newborn.

The main strength of the present study was the uniform diagnostic procedure for GDM, based on universal screening with a 75-g OGTT, enabling identification of a rather large cohort of women with test results over the entire glucose scale. In our previous report from the Mamma Study, suggesting that moderately increased glucose levels may also affect pregnancy outcome, adjustments for BMI were not performed because the information was not available at the time [11]. In light of the present findings, it is reasonable to assume that adjustment for BMI would have attenuated the results to some extent. However, as the current study showed that the correlation between BMI and glucose levels was rather weak, it is not likely that the results would be 
heavily influenced from BMI. Furthermore, since the control group in the previous study included only one twenty-fourth of consenting women with normal glucose tolerance during pregnancy, the material did not allow prediction analysis. We have previously shown that maternal characteristics such as age, parity and smoking-in addition to BMI and maternal glucose status-influence fetal growth during the last trimester [26]. The logistic regression modelling identified the independent variables available from the register that are important and can help in the prediction of LGA births.

It could be argued that women with glucose levels in the IGT range and above, receiving some kind of advice or treatment during pregnancy may have biased the results. However, it is likely that the risk of LGA births would have increased even more if these women had not been taken care of. Another possible weakness of the study was the lack of information regarding ethnicity. Disparities in ethnicity/race may affect the impact of obesity and glucose status on perinatal outcomes [27-29]. Furthermore, the prediction model might have been more powerful if maternal weight gain during pregnancy had been considered. Both maternal pre-pregnancy obesity and excessive gestational weight gain lead to increased risk of adverse pregnancy outcomes, including LGA. Overall, the associations between maternal pre-pregnancy obesity and adverse pregnancy outcomes appear to be stronger than those between excessive gestational weight gain and adverse pregnancy outcomes [30], although some studies have indicated that gestational weight gain is of greater importance [5, 31].

\section{Conclusions}

Based on the present material, we conclude that maternal BMI had a greater impact on the prediction of LGA birth than the 2-h glucose level of the OGTT. The overall performance of the full prediction model, also taking other risk factors into account, was satisfactory. The data highlight the importance of targeting healthy body weight in pregnant women and closer monitoring of weight during pregnancy as a strategy for reducing the risk of excessive fetal growth. A number of intervention trials have been published and show heterogeneous results in efficacy in reducing excess gestational weight gain [32, 33]. Adequately powered intervention studies are needed to provide evidence-based guidelines to facilitate pregnant women in achieving weight gain within recommended limits with the aim to reduce neonatal adiposity.

\section{Abbreviations}

AGA: adequate-for-gestational-age; AUC: area under the ROC curve; BMI: body mass index; Cl: confidence interval; GDM: gestational diabetes mellitus; HAPO: Hyperglycemia and Adverse Pregnancy Outcome;
IADPSG: International Association of Diabetes and Pregnancy Study Groups; IGT: impaired glucose tolerance; LGA: large-for-gestational-age; OGTT: oral glucose tolerance test; OR: odds ratio; PRS: Perinatal Revision South; ROC curve: receiver-operating characteristic curve; SD: standard deviation; SGA: small-for-gestational-age; WHO: World Health Organization.

\section{Competing interests}

The authors declare that they have no competing interests.

\section{Authors'contributions}

$\mathrm{KB}$ contributed to the conceptual design, acquired and interpreted the data, and drafted the article. EA contributed to the conceptual design, acquired and interpreted data and critically revised the manuscript. RC contributed to the conceptual design, interpreted the data and helped draft the article. $\mathrm{Cl}$ contributed to the conceptual design, interpreted data and critically revised the manuscript. KK conceived and designed the study, analyzed and interpreted the data, and critically revised the manuscript. All the authors approved the final version and they vouch for the accuracy of the manuscript according to the guidelines given.

\section{Acknowledgements}

This study was supported by grants from the Research Funds of Malmö University Hospital and from Skåne County Council Research and Development Foundation.

\section{Author details}

'Department of Clinical Sciences Malmö, Lund University, Malmö, Sweden. ${ }^{2}$ Department of Endocrinology, Skåne University Hospital, Malmö, Sweden. ${ }^{3}$ Department of Clinical Sciences Lund, Lund University, Lund, Sweden. "Department of Obstetrics and Gynecology, Office for Healthcare "Kryh", Ystad SE-27182, Sweden. ${ }^{5}$ Department of Obstetrics and Gynecology, Office for Healthcare "Sund", Helsingborg, Sweden.

Received: 16 June 2015 Accepted: 21 October 2015

Published online: 29 October 2015

\section{References}

1. Huda SS, Brodie LE, Sattar N. Obesity in pregnancy: prevalence and metabolic consequences. Semin Fetal Neonatal Med. 2010;15(2):70-6.

2. Chu SY, Callaghan WM, Kim SY, Schmid CH, Lau J, England LJ, et al. Maternal obesity and risk of gestational diabetes mellitus. Diabetes Care. 2007;30(8):2070-6.

3. HAPO Study Cooperative Research Group. Hyperglycaemia and Adverse Pregnancy Outcome (HAPO) Study: associations with maternal body mass index. BJOG. 2010;117(5):575-84.

4. Catalano PM, Mclntyre HD, Cruickshank JK, McCance DR, Dyer AR, Metzger BE, et al. The hyperglycemia and adverse pregnancy outcome study: associations of GDM and obesity with pregnancy outcomes. Diabetes Care. 2012;35(4):780-6.

5. Kim SY, Sharma AJ, Sappenfield W, Wilson HG, Salihu HM. Association of maternal body mass index, excessive weight gain, and gestational diabetes mellitus with large-for-gestational-age births. Obstet Gynecol. 2014;123(4):737-44.

6. Weissmann-Brenner A, Simchen MJ, Zilberberg E, Kalter A, Weisz B, Achiron R, et al. Maternal and neonatal outcomes of large for gestational age pregnancies. Acta Obstet Gynecol Scand. 2012;91(7):844-9.

7. Henriksen T. The macrosomic fetus: a challenge in current obstetrics. Acta Obstet Gynecol Scand. 2008;87(2) :134-45.

8. Surkan PJ, Hsieh CC, Johansson AL, Dickman PW, Cnattingius S. Reasons for increasing trends in large for gestational age births. Obstet Gynecol. 2004;104(4):720-6.

9. Ekblad M, Gissler M, Korkeila J, Lehtonen L. Trends and risk groups for smoking during pregnancy in Finland and other Nordic countries. Eur J Public Health. 2014;24(4): 544-51.

10. Anderberg E, Källen K, Berntorp K, Frid A, Aberg A. A simplified oral glucose tolerance test in pregnancy: compliance and results. Acta Obstet Gynecol Scand. 2007;86(12):1432-6.

11. Anderberg E, Källen K, Berntorp K. The impact of gestational diabetes mellitus on pregnancy outcome comparing different cut-off criteria for abnormal glucose tolerance. Acta Obstet Gynecol Scand. 2010;89(12):1532-7 
12. Lind T, Phillips PR. Influence of pregnancy on the 75-g OGTT. A prospective multicenter study. The diabetic pregnancy study group of the European association for the study of diabetes. Diabetes. 1991;40 Suppl 2:8-13.

13. Burnett RW, D'Orazio P, Fogh-Andersen N, Kuwa K, Kulpmann WR, Larsson L, et al. IFCC recommendation on reporting results for blood glucose. Clin Chim Acta. 2001;307(1-2):205-9.

14. Molin J. A regional perinatal database in southern Sweden-a basis for quality assurance in obstetrics and neonatology. Acta Obstet Gynecol Scand Suppl. 1997;164:37-9.

15. Maršál K, Persson P-H, Larsen T, Lilja H, Selbing A, Sultan B. Intrauterine growth curves based on ultrasonically estimated foetal weihts. Acta Pediatr. 1996;85(7):843-8.

16. DeLong ER, DeLong DM, Clarke-Pearson DL. Comparing the areas under two or more correlated receiver operating characteristic curves: a nonparametric approach. Biometrics. 1988;44(3):837-45.

17. Jiwani A, Marseille E, Lohse N, Damm P, Hod M, Kahn JG. Gestational diabetes mellitus: results from a survey of country prevalence and practices. J Matern Fetal Neonatal Med. 2012;25(6):600-10.

18. World Health Organization. Definition, diagnosis and classification of diabetes mellitus and its complications. Part I: diagnosis and classification of diabetes mellitus. Geneva: World Health Organization; 1999.

19. Jensen DM, Damm P, Sorensen B, Molsted-Pedersen L, Westergaard JG, Ovesen $P$, et al. Pregnancy outcome and prepregnancy body mass index in 2459 glucose-tolerant Danish women. Am J Obstet Gynecol. 2003;189(1):239-44.

20. HAPO Study Cooperative Research Group, Metzger BE, Lowe LP, Dyer AR, Trimble ER, Chaovarindr U, et al. Hyperglycemia and adverse pregnancy outcomes. N Engl J Med. 2008;358(19):1991-2002.

21. International Association of Diabetes and Pregnancy Study Groups Consensus Panel, Metzger BE, Gabbe SG, Persson B, Buchanan TA, Catalano $\mathrm{PA}$, et al. International association of diabetes and pregnancy study groups recommendations on the diagnosis and classification of hyperglycemia in pregnancy. Diabetes Care. 2010;33(3):676-82.

22. Houshmand A, Jensen DM, Mathiesen ER, Damm P. Evolution of diagnostic criteria for gestational diabetes mellitus. Acta Obstet Gynecol Scand. 2013;92(7):739-45.

23. Sacks DA, Hadden DR, Maresh M, Deerochanawong C, Dyer AR, Metzger BE, et al. Frequency of gestational diabetes mellitus at collaborating centers based on IADPSG consensus panel-recommended criteria: the Hyperglycemia and Adverse Pregnancy Outcome (HAPO) Study. Diabetes Care. 2012;35(3):526-8.

24. Lindqvist $M$, Persson $M$, Lindkvist $M$, Mogren I. No consensus on gestational diabetes mellitus screening regimes in Sweden: pregnancy outcomes in relation to different screening regimes 2011 to 2012, a cross-sectional study. BMC Pregnancy Childbirth. 2014;14:185.

25. Ignell C, Berntorp K. Evaluation of the relationship between capillary and venous plasma glucose concentrations obtained by the HemoCue Glucose $201+$ system during an oral glucose tolerance test. Scand J Clin Lab Invest. 2011;71(8):670-5.

26. Lindell G, Maršál K, Källen K. Impact of maternal characteristics on fetal growth in the third trimester: a population-based study. Ultrasound Obstet Gynecol. 2012;40(6):680-7.

27. Marshall NE, Guild C, Cheng YW, Caughey AB, Halloran DR. Racial disparities in pregnancy outcomes in obese women. J Matern Fetal Neonatal Med. 2014;27(2):122-6.

28. Oteng-Ntim E, Kopeika J, Seed P, Wandiembe S, Doyle P. Impact of obesity on pregnancy outcome in different ethnic groups: calculating population attributable fractions. PLoS One. 2013;8(1):e53749.

29. Nguyen BT, Cheng YW, Snowden JM, Esakoff TF, Frias AE, Caughey AB. The effect of race/ethnicity on adverse perinatal outcomes among patients with gestational diabetes mellitus. Am J Obstet Gynecol. 2012;207(4):322. e1-6.

30. Gaillard R, Felix JF, Duijts L, Jaddoe WW. Childhood consequences of maternal obesity and excessive weight gain during pregnancy. Acta Obstet Gynecol Scand. 2014;93(11):1085-9.
31. Jensen DM, Ovesen P, Beck-Nielsen H, Molsted-Pedersen L, Sorensen B, Vinter C, et al. Gestational weight gain and pregnancy outcomes in 481 obese glucose-tolerant women. Diabetes Care. 2005;28(9):2118-22.

32. Ronnberg AK, Nilsson K. Interventions during pregnancy to reduce excessive gestational weight gain: a systematic review assessing current clinical evidence using the Grading of Recommendations, Assessment, Development and Evaluation (GRADE) system. BJOG. 2010;117(11) :1327-34.

33. Poston L, Harthoorn LF, Van Der Beek EM. Contributors to the ILSI Europe workshop. Obesity in pregnancy: implications for the mother and lifelong health of the child. A consensus statement. Pediatr Res. 2011;69(2):175-80.

\section{Submit your next manuscript to BioMed Central and take full advantage of:}

- Convenient online submission

- Thorough peer review

- No space constraints or color figure charges

- Immediate publication on acceptance

- Inclusion in PubMed, CAS, Scopus and Google Scholar

- Research which is freely available for redistribution 